Research Article

\title{
Experimental Study on the Progressive Collapse Resistance of Two-Storey Half-Scale Fabricated Reinforced Concrete Column-Steel Beam Composite Frame Structure
}

\author{
Youquan Liu, Jingang Xiong $\mathbb{D}$, and Jiancong Wen \\ School of Civil Engineering and Architectural, Nanchang University, Nanchang, China \\ Correspondence should be addressed to Jingang Xiong; xiongjingang@ncu.edu.cn
}

Received 28 June 2021; Revised 24 August 2021; Accepted 25 August 2021; Published 10 September 2021

Academic Editor: Emanuele Brunesi

Copyright (c) 2021 Youquan Liu et al. This is an open access article distributed under the Creative Commons Attribution License, which permits unrestricted use, distribution, and reproduction in any medium, provided the original work is properly cited.

\begin{abstract}
Progressive collapse behavior of case-in-place concrete and steel frame structures has been extensively investigated over the past years. However, studies on progressive collapse resistance and characteristics of prefabricated RCS composite frame structure (space frame) are limited. In this study, a half-scale prefabricated RCS space frame structure (two-storey, $1 \times 2$-bay) was designed and manufactured and then tested through the sudden failure of the long-side central column. The weakened part of failure column was rapidly pulled out using vehicle traction force, and displacement was obtained with a dynamic data acquisition instrument supplemented by high-speed camera to record the deformation process of the structure. Additionally, the remaining structure displacement variation and the beam-to-column connections of fem model under progressive collapse were simulated using SAP2000. The FEA results were compared with the experimental results to verify the effectiveness of the numerical analysis. Experimental results demonstrated that the prefabricated RCS composite frame structure designed in accordance with Chinese building codes shows improved resistance to progressive collapse. The dynamic effect demonstrates no significant influence on the prefabricated RCS composite frame structure, and the suggested dynamic amplification coefficient is 1.28. Steel plates (A, B, and C) of the beam-to-column connection are the weak part of the structural failure, and appropriate measures should be applied to strengthen the steel plate of the beam-to-column connection when the prefabricated RCS composite frame structure is designed to resist progressive collapse. SAP2000 FEM program verified that the numerical simulation results are basically consistent with the experimental results.
\end{abstract}

\section{Introduction}

Prefabricated reinforced concrete column-steel beam composite frame structure, referred to as prefabricated RCS composite frame structure, comprises precast reinforced concrete columns, steel beams, and composite floor slabs in the building site and is an important branch of the assembly structure system. The prefabricated RCS composite frame structure can optimize advantages of steel and reinforced concrete members, is a low-cost and high-efficiency structural style [1] with broad development prospects, and is a dominant structural system in line with the development trend of construction industrialization.

The spread of an initial local failure from element to element eventually results in the collapse of an entire structure or a disproportionately large part of it. This phenomenon is called progressive collapse. The majority of studies on prefabricated RCS composite frame structures focus on the connection structure of steel beam-reinforced concrete column, joint shear mechanism [2], and seismic performance. However, research on the progressive collapse resistance of prefabricated RCS composite frame structures under accidental events, such as explosion and impact, is still limited. Serious casualties and large economic losses are incurred once the building structure progressively collapses.

The American scholar Shimizu first proposed the concept of reinforced concrete column-steel beam composite frame structure system in the 1970s. American engineering circle began to use RCS composite structures in high-rise buildings in the 1980s. Griffis [3] investigated the interaction 
between steel and concrete as well as the performance of beam-to-column connection in the RCS composite frame in 1985. Sheikh et al. $[4,5]$ carried out static experimental research on RCS composite frame beam-to-column middle joint while focusing on the analysis of strength and stiffness of the joint and provided the formula for calculating the shear strength of the RCS joint in 1989. Kanno et al. [6, 7] carried out seismic performance experimental study on 11 specimens with a large proportion of composite joints in high-intensity areas and conducted an in-depth study on the failure mode of RCS composite frame beam-to-column joint in 1993. Parra-Montesinos and Wight [8] carried out an experimental study on the edge joint of the middle layer of a 3/4-ratio RCS composite frame under cyclic load in 2000. Liang and Gustavo [9] performed an experimental study of four RCS composite joints under low cyclic reverse load, analyzed the ground motion of the RCS frame system, and explored the energy dissipation capacity, hysteretic performance, interlayer displacement, and joint deformation of specimens in 2004. Cheng and Chen [10] completed a seismic performance experimental study under low cyclic load on six RCS joints and examined parameters, such as plane joint, spatial joint, orthogonal beam, and form of stirrups in joint areas in 2005. Luis et al. [11] accomplished a low cyclic loading experimental study on two RCS top middle joint specimens and assessed anchoring requirement of longitudinal bars and other structural measures in the joint area in 2006.

The collapse of the apartment building Ronan Point in London in 1968 first attracted the attention of researchers to progressive collapses. British researchers wrote the requirement into building codes in 1970 to prevent structural collapse. Canada added a clause in the building code in 1975 to prevent structural progressive collapse. Sweden, Denmark, Holland, and other national standards have also included a clause on progressive collapse. Progressive collapses increasingly attracted research attention in the United States after the Murrah Federal Building Incident in 1995 and the World Trade Center Incident in New York in 2001 [12-15]. The United States General Services Administration (GSA) and the Department of Defense (DOD) $[16,17]$ have developed design standards to prevent the progressive collapse of structures. Japan, Russia, and other countries have also established design rules on structural progressive collapse control [18]. Xiong et al. [19] completed a progressive collapse experimental study on a reinforced concrete space frame structure with the long-side central column and the corner column failing at the bottom and analyzed the resistance mechanism of progressive collapse in 2012-2013.

The "new RCS beam-to-column connection" [20] is used as the beam-to-column connection type of the experimental model, and a half-scale prefabricated RCS space frame structure (two-storey, $1 \times 2$-bay) is manufactured in this study. Failure column (2A) was suddenly pulled out via vehicle traction force, as illustrated in Figure 1, the displacement was obtained with a dynamic data acquisition instrument, and a high-speed camera was used to record the deformation process of the structure to explore the progressive collapse resistance and characteristics of the

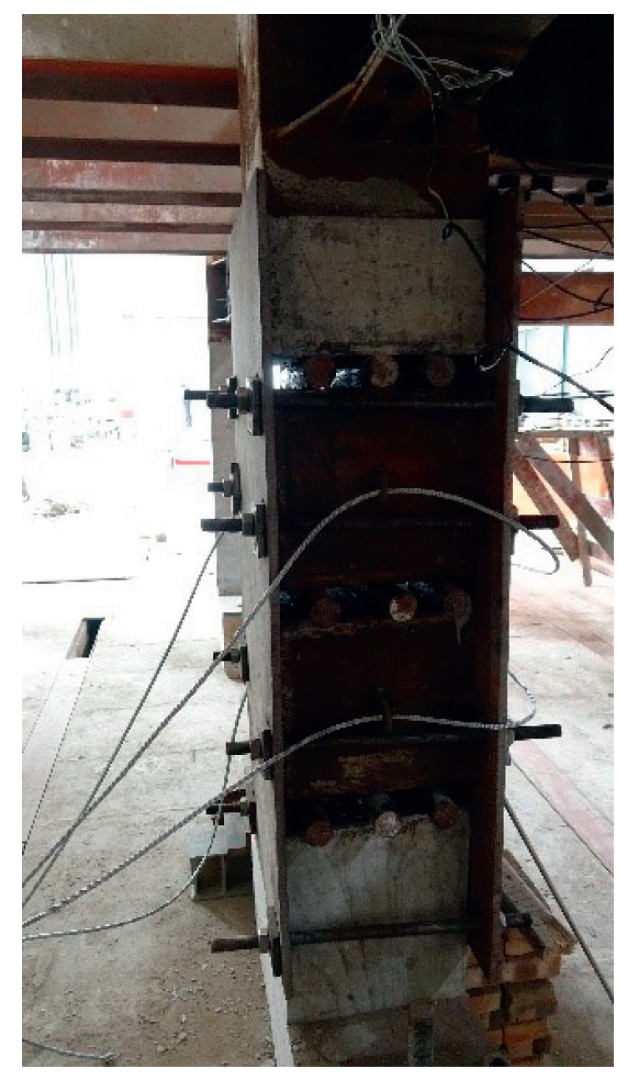

Figure 1: Constructional details of 2A.

prefabricated RCS composite frame structure. Compared with hydrogen gas-gun impact method proposed by Xiao et al. [21] of University of Southern California and the "Explosion Demolition Method" proposed by Qing-Feng and Wei Jian [22], the proposed method of using car traction in this study presents characteristics of high safety and strong operability.

The experimental results revealed the progressive collapse resistance and characteristics of the fabricated RCS composite frame structure. This study also confirmed that the steel plate of the beam-to-column connection is the weak part of the prefabricated RCS composite frame structure failure.

\section{Experimental Program}

The beam-to-column connection of the prototype of fabricated RCS composite frame structure adopts the "new RCS beam-to-column connection" [20], which was developed by our research group. The A-B span at the bottom of the fabricated two-storey RCS composite frame structure prototype was used as the experimental model and scaled down to one-half.

2.1. Type of "New RCS Beam-to-Column Connection." The "new RCS beam-to-column connection" [20] is composed of joint steel hoop $(350 \mathrm{~mm} \times 350 \mathrm{~mm} \times 500 \mathrm{~mm} \times 12 \mathrm{~mm})$, internal welded cross web (thickness: $10 \mathrm{~mm}$ ), level stiffeners (thickness: $9 \mathrm{~mm}$ ), and outer welded cantilever beam section 
(length: $2000 \mathrm{~m}$ ). Specifications of the "new RCS beam-tocolumn connection" [20] are listed in Table 1. Constructional details and connection diagram of the "new RCS beam-to-column connection" [20] are shown in Figures 2 and 3 , respectively. The sketch of concrete is shown in Figure 4.

2.2. Experimental Perspective. The structural prototype in this study is a fabricated RCS composite frame structure (five-storey, $3 \times 4$-bay), which is designed in accordance with the requirements of Chinese building codes [23-27]. Live and dead load values on floors and roof are 2.0 and $2.0 \mathrm{KN} /$ $\mathrm{m}^{2}$, respectively. The concrete grade is C40, the steel bar is HRB335, and the steel member is Q345. The cross section size of the steel beam is $600 \mathrm{~mm} \times 300 \mathrm{~mm} \times 13 \mathrm{~mm} \times$ $18 \mathrm{~mm}$, the cross section size of the concrete column is $700 \mathrm{~mm} \times 700 \mathrm{~mm}$, and the floor slab is the channeled steel plate composite floor with a thickness of $100 \mathrm{~mm}$. The seismic design intensity is 7 degrees, and the corresponding design peak ground acceleration (PGA) with a $10 \%$ probability of exceedance in 50 years is $0.1 \mathrm{~g}$, where $\mathrm{g}$ is the acceleration of gravity. The site classification of the building is class II, and the eigenperiod is $0.40 \mathrm{~s}$. Perspective and plan views of the prototype structure are shown in Figures 5(a) and $5(b)$.

2.3. Experimental Model. The A-B span at the bottom of the fabricated two-storey RCS composite frame structure prototype was used as the experimental model and scaled down to one-half, and the membrane effect of the slab was not considered. The size of the concrete column is $350 \mathrm{~mm} \times 350 \mathrm{~mm}$; the size of the steel beam is $300 \mathrm{~mm} \times 150 \mathrm{~mm} \times 6.5 \mathrm{~mm} \times 9 \mathrm{~mm}$, as illustrated in Figure 6 , with 3 and $3 \mathrm{~m}$ spans in two orthogonal directions; the height of the first floor (second floor) is $2 \mathrm{~m}(1.8 \mathrm{~m})$; the ground beam is used to replace the foundation; and the membrane effect of the slab was not considered. A series of standard cubic concrete was tested, and the average compressive strength $\left(f_{c u}\right)$ was $39.8 \mathrm{MPa}$, the elastic modulus of steel was $201 \mathrm{GPa}$, and Poisson's ratio was 0.28. Experimental model and photo of scene reinforcement are shown in Figures 7 and 8, respectively. The column and foundation reinforcement are illustrated in Figure 9.

\section{Experimental Scheme}

3.1. Loading Scheme. Beam-to-column connection in the experimental model is complex, and the accurate calculation of the weight of the heap is difficult to achieve. The design load values in the area of maximum influence of the RCS structure prototype (1-5 storeys) were applied to the area of maximum influence of the experimental model to explore the progressive collapse resistance and characteristics of the prefabricated RCS composite frame structure. The load plan view is illustrated in Figure 10. The discarded I-shaped steel beam is evenly placed on the steel frame beam, and the weight of the heap is exerted on the discarded I-shaped steel beam as close to the failure column as possible. The weight of the heap is $140.4 \mathrm{KN}$. The load photo of the scene is presented in Figure 11.

3.2. Removed Failure Column Scheme. The weakened part of the failure column is composed of embedded steel plate 1 , steel roll bar 1, steel column 1, steel roll bar 2, steel column 2, steel roll bar 3, and embedded steel plate 2 from top to bottom. The lateral support steel plate is fixed in the $Y$ direction. The photo of failure column is shown in Figure 12. Accidental crash events are a condition that can cause progressive collapse. Vehicle traction force is utilized to pull out the weakened part of the failure column rapidly and simulate accidental crash events. The lateral support steel plate was removed, the wire rope was passed through reserved rings on the two steel columns, and the other end was fixed on the rear end of a car before conducting the experiment. Photos of the failure process taken by a high-speed camera are shown in Figure 13. The experimental results showed that the traction force provided by the car can pull out the weakened part of the failure column within 0.1 times the vertical period, thereby verifying the effectiveness of the failure process.

3.3. Data Test Scheme. The dynamic data acquisition instrument was used to obtain displacement, and a highspeed camera was used to record the deformation process of the structure to meet the requirements of data acquisition. Displacement sensors with a range of $100 \mathrm{~mm}$ are installed in $X$ direction of column $1 \mathrm{~A}$ and $Y$ direction of column $2 \mathrm{~B}$ on the first storey and $Z$ direction of the failure column (2A) top. Displacement test points are illustrated in Figure 14.

\section{Experimental Results}

4.1. Displacement Results and Analysis. Time history curves of the $Z$ direction displacement on the top of the failure column (2A) are shown in Figures 15(a) and 15(b). The vertical displacement instantly reaches $2.255 \mathrm{~mm}$ from $0 \mathrm{~s}$ to $0.02 \mathrm{~s}$ because the diameter of the bolt hole is larger than $2 \mathrm{~mm}$ in the M20 bolt diameter. The rate at which the vertical displacement increases is slower than the previous $0.02 \mathrm{~s}$, the maximum vertical displacement is $4.044 \mathrm{~mm}$, and the vertical displacement appears to vibrate in the $Z$ direction from $0.533 \mathrm{~s}$ to $4.16 \mathrm{~s}$ and then enters the stable growth period of the beam mechanism after $4.16 \mathrm{~s}$ when the bolt comes into contact with the inner wall of the bolt hole. The bolt microslip drives the displacement to increase continuously in the $Z$ direction, the final displacement in the $Z$ direction tends toward $10.17 \mathrm{~mm}$ and stabilizes after $1034 \mathrm{~s}$, and the remaining RCS structure is in the resistance stable state provided by the beam mechanism as time progresses.

Time history curves of column $2 \mathrm{~B}$ in the $Y$ direction are shown in Figures 16(a) and 16(b). The initial response time of column $2 \mathrm{~B}$ displacement in the $Y$ direction lagging behind the failure column $(2 \mathrm{~A})$ in the $Z$ direction is approximately $0.146 \mathrm{~s}$ because the diameter of the bolt hole is larger than that of the M20 bolt at $2 \mathrm{~mm}$. Column 2B displacement in 
TABLe 1: Specifications of "new RCS beam-to-column connection."

\begin{tabular}{lcc}
\hline Name & Size $(\mathrm{mm})$ & Height/thickness/length $(\mathrm{mm})$ \\
\hline Joint steel hoop & $350 \times 350 \times 12$ & Height: 500 \\
Cross web & $500 \times 326$ & Thickness: 10 \\
Level stiffener & $20 \times 70$ & Thickness: 9 \\
Cantilever beam section & $300 \times 150 \times 6.5 \times 9$ & Length: 200 \\
Steel plate A & $315 \times 150$ & Thickness: 8 \\
Steel plate B & $315 \times 70$ & Thickness: 8 \\
Steel plate C & $355 \times 240$ & Thickness: 8 \\
\hline
\end{tabular}

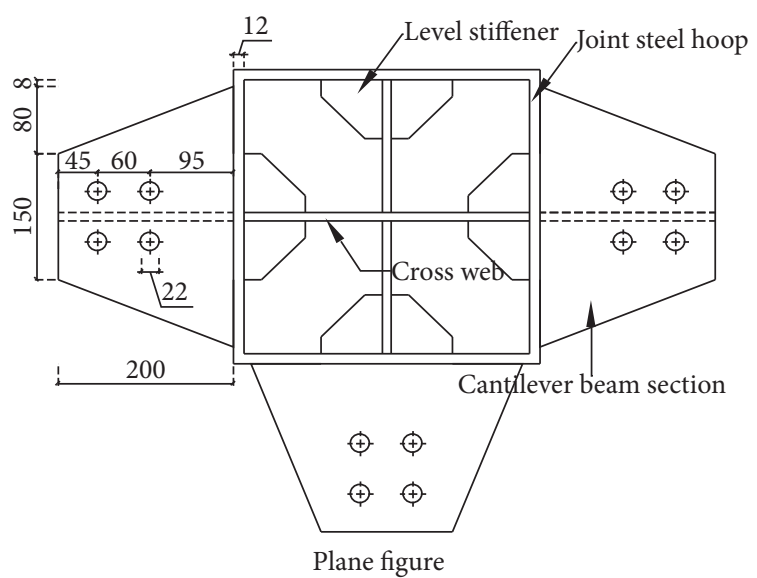

(a)

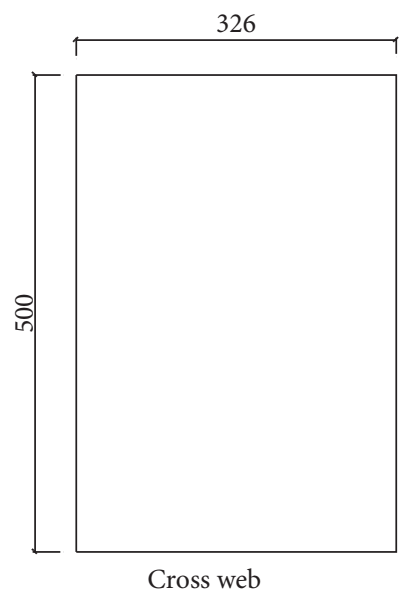

(c)

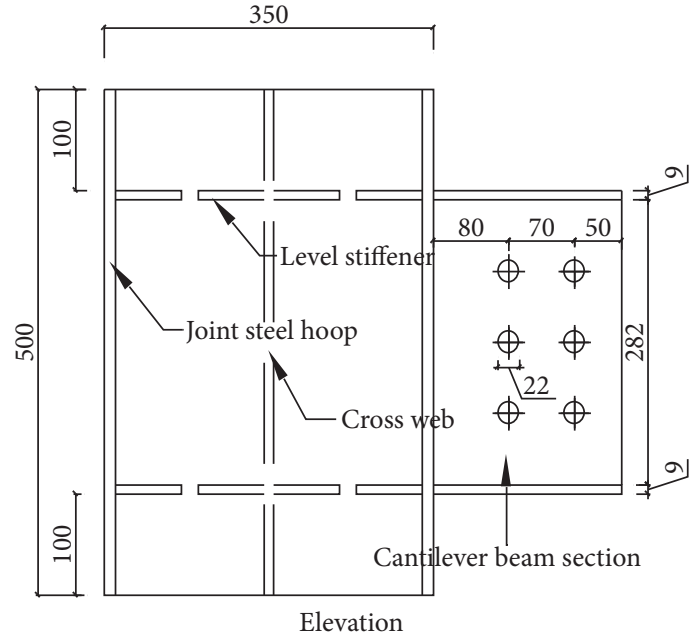

(b)

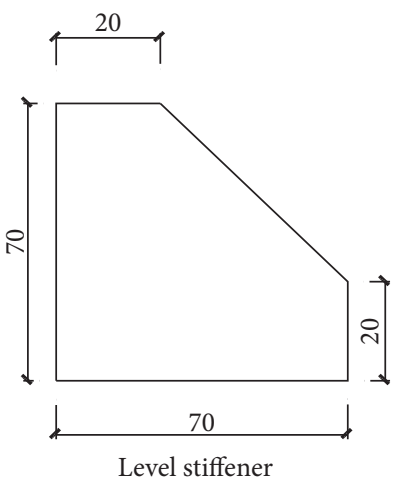

(d)

Figure 2: Continued. 


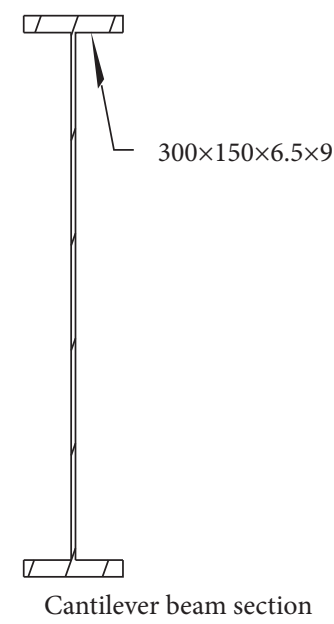

(e)

FIgURE 2: Constructional details of "new RCS beam-to-column connection."

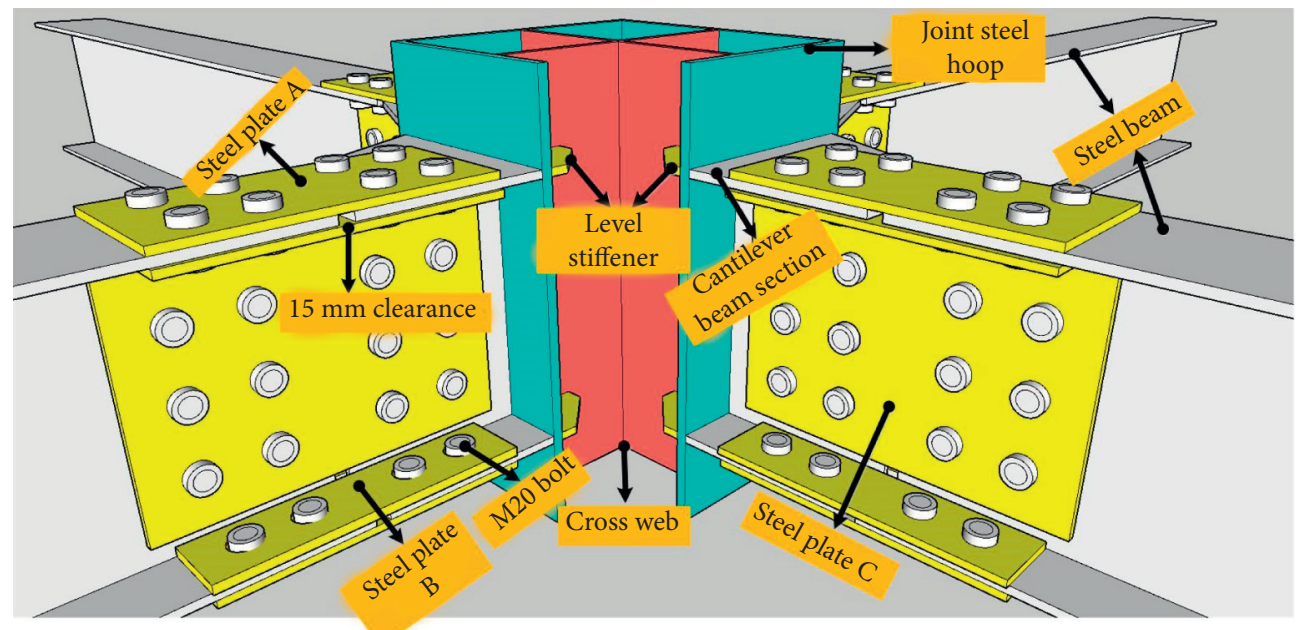

FIgURE 3: Connection diagram of "new RCS beam-to-column connection."

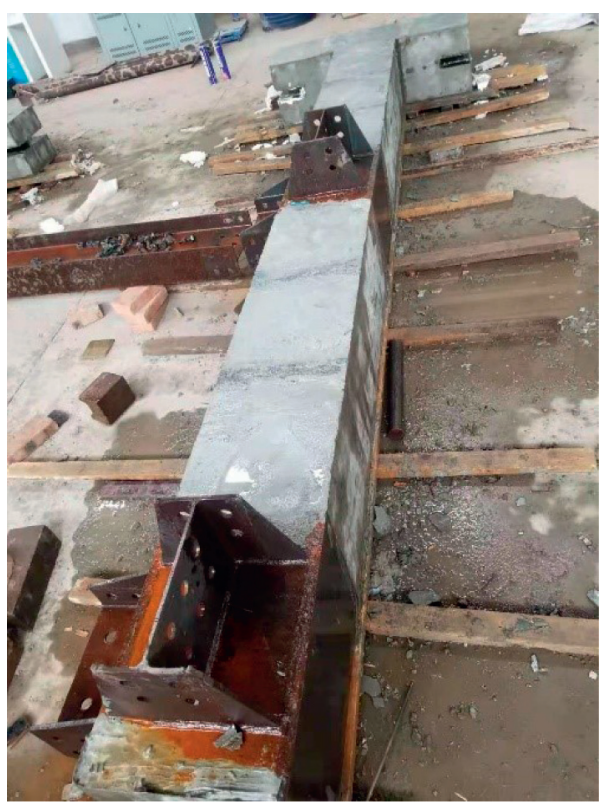

FIGURE 4: Sketch of the concrete. 


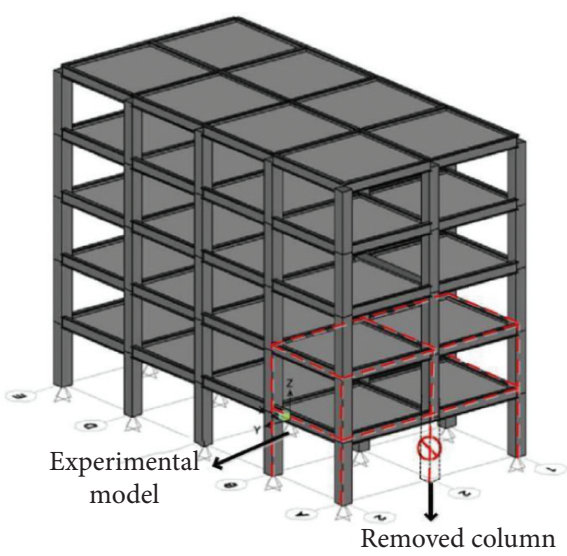

(a)

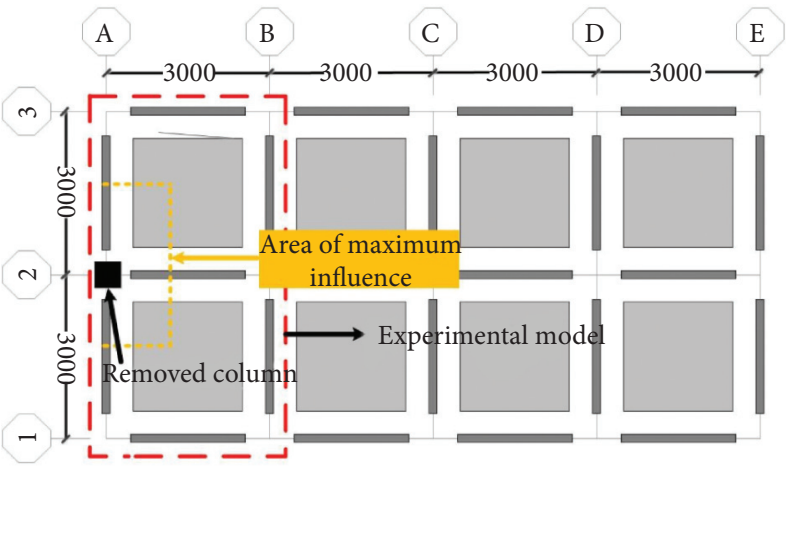

(b)

Figure 5: The prototype structure (units: mm). (a) Perspective view. (b) Plan view.

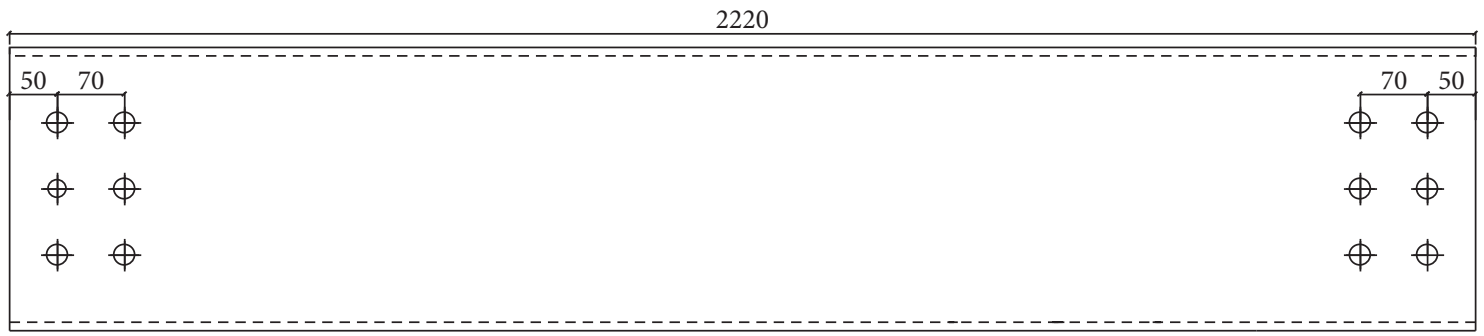

(a)

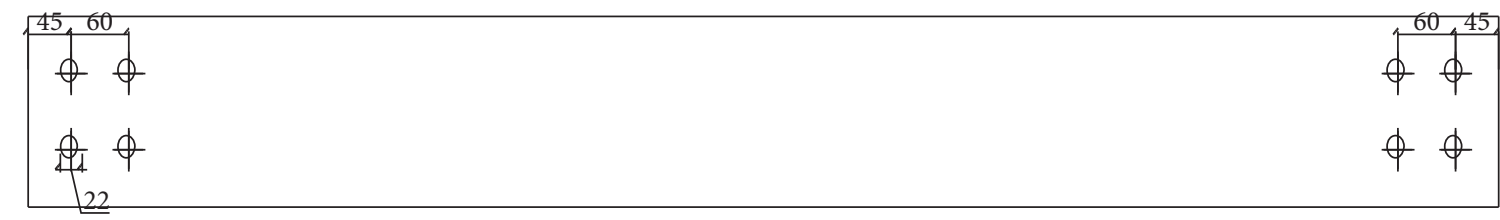

(b)

Figure 6: Details of the steel beam. (a) Front view of beam. (b) Plan view of beam.

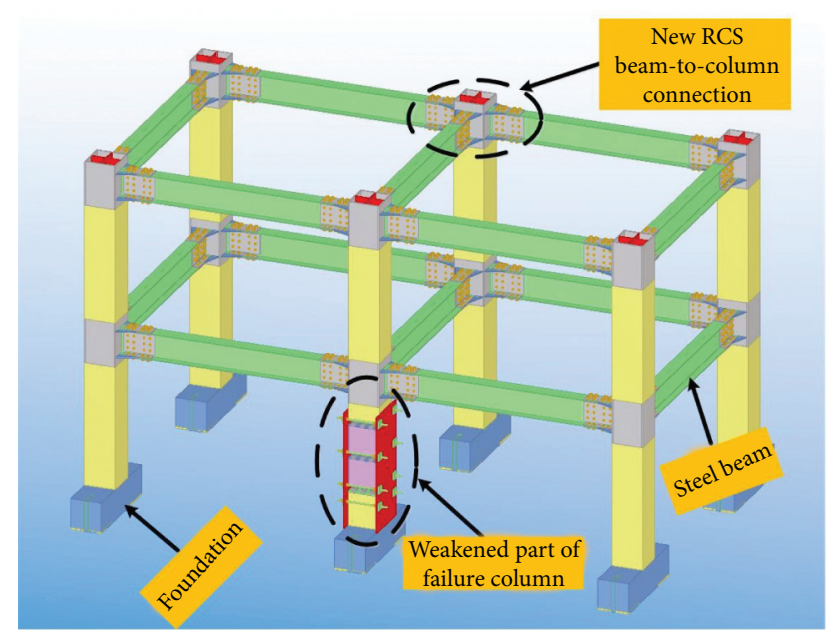

FIgURE 7: Experimental model.

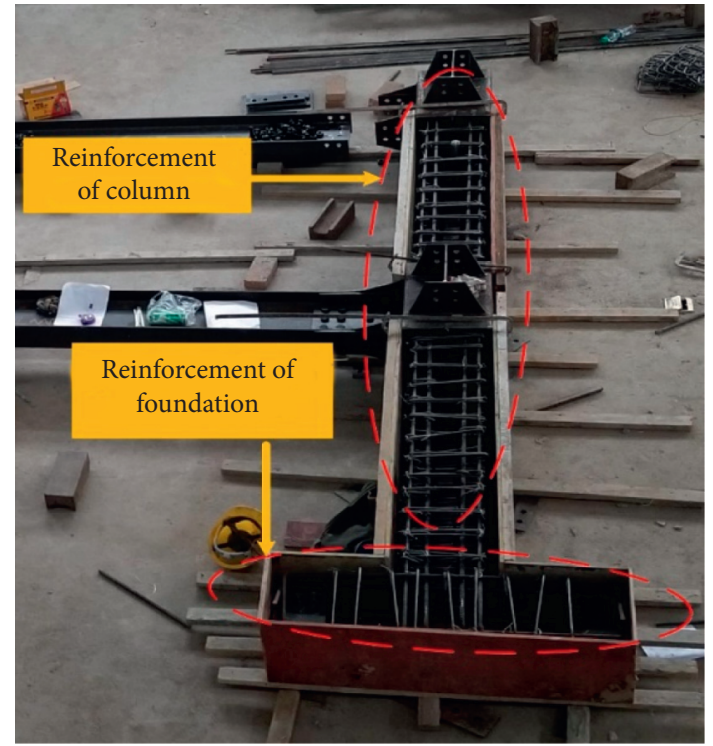

Figure 8: Photo of the scene reinforcement. 


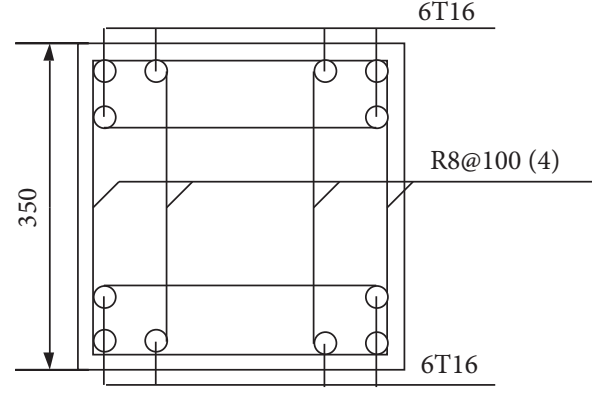

(a)

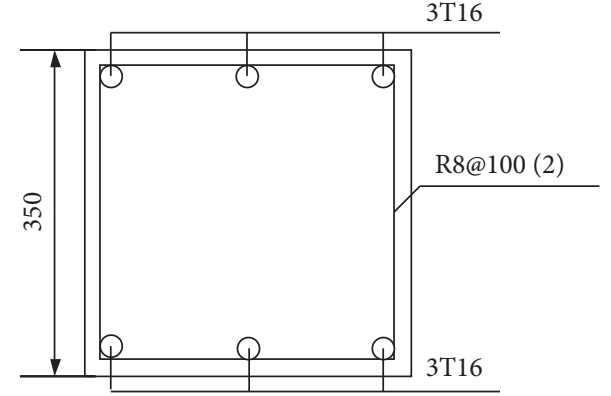

(b)

FIgUre 9: (a) Column reinforcement and (b) foundation reinforcement.

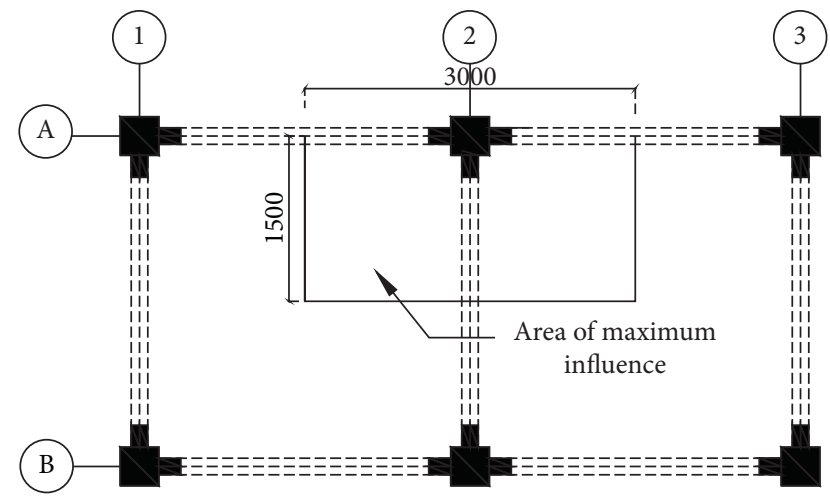

Figure 10: Load plan view.

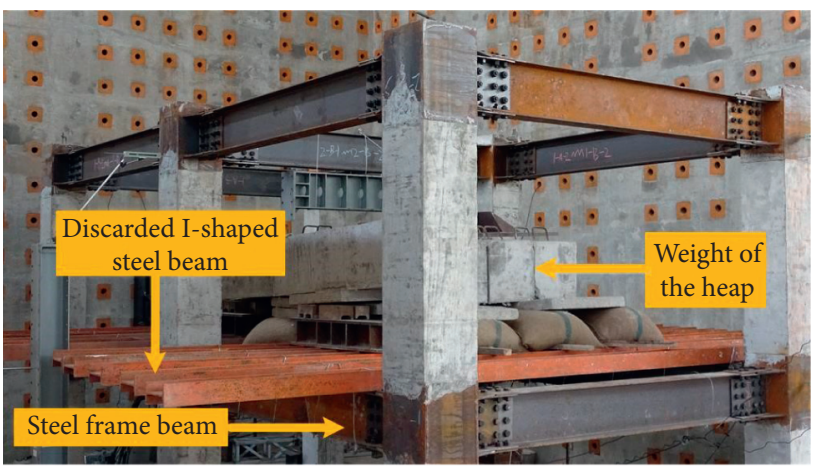

Figure 11: Load photo of the scene.

the $Y$ direction instantly reaches $2.478 \mathrm{~mm}$ from $0 \mathrm{~s}$ to $0.684 \mathrm{~s}$, appears to swing in the $Y$ direction between 0.684 and $1.273 \mathrm{~s}$ with a maximum swing displacement of $2.555 \mathrm{~mm}$, and enters the stable growth period between 1.273 and $1039 \mathrm{~s}$. The growth stops when the displacement reaches $6.60 \mathrm{~mm}$ in $1039 \mathrm{~s}$. The swing time of column 2B displacement in the $Y$ direction is shorter than the vertical vibration time of column $2 \mathrm{~A}$ displacement. The author believes that vibration is transmitted from column $2 \mathrm{~A}$ to column $2 \mathrm{~B}$ and vibration energy is consumed during transmission.

Time history curves of column $1 \mathrm{~A}$ in the $X$ direction are shown in Figures 17(a) and 17(b). Column 1A displacement

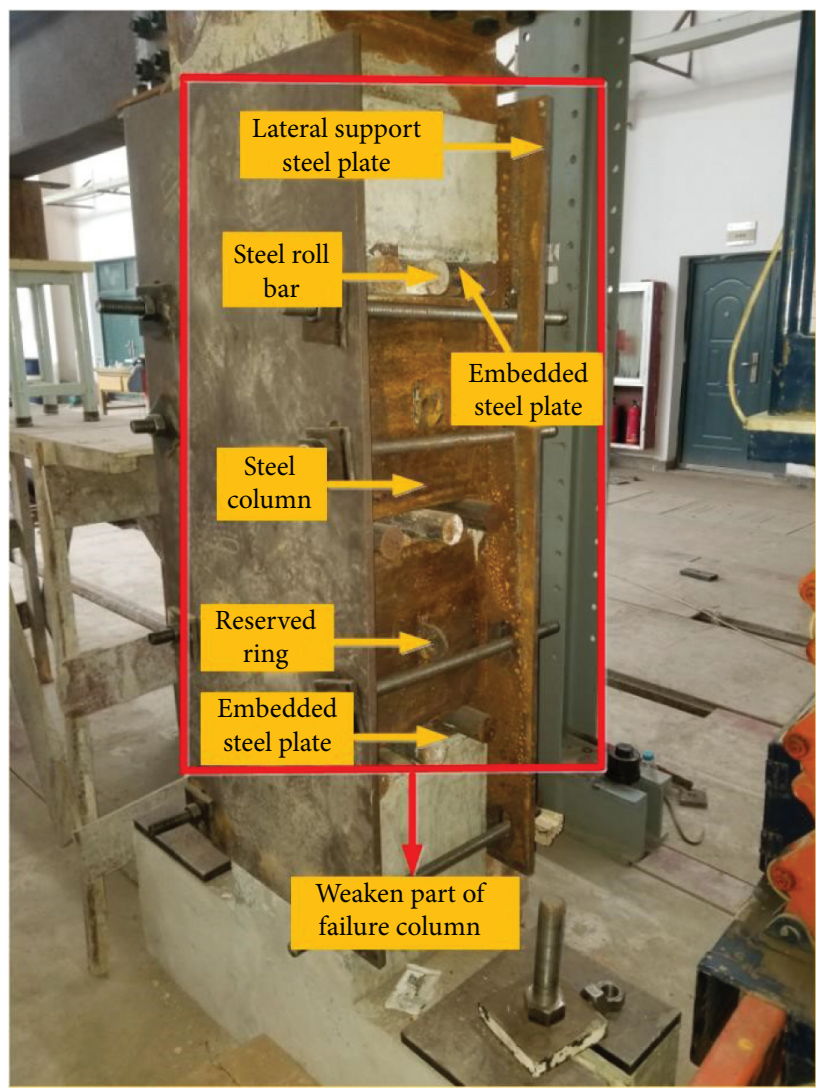

Figure 12: Photo of the failure column.

in the $X$ direction instantly reaches $1.012 \mathrm{~mm}$ from $0 \mathrm{~s}$ to $0.683 \mathrm{~s}$, appears to swing in the $X$ direction between 0.683 and $1.071 \mathrm{~s}$ with a maximum swing displacement of $1.032 \mathrm{~mm}$, and enters the stable growth period between 1.071 and $1002 \mathrm{~s}$. The growth stops when the displacement reaches $4.275 \mathrm{~mm}$ in $1002 \mathrm{~s}$.

4.2. Deformation and Analysis of Steel Plates ( $A, B$, and $C$ ). Joint numbers are shown in Figure 18 to facilitate the description of the deformation of steel plates $(\mathrm{A}, \mathrm{B}$, and C). 


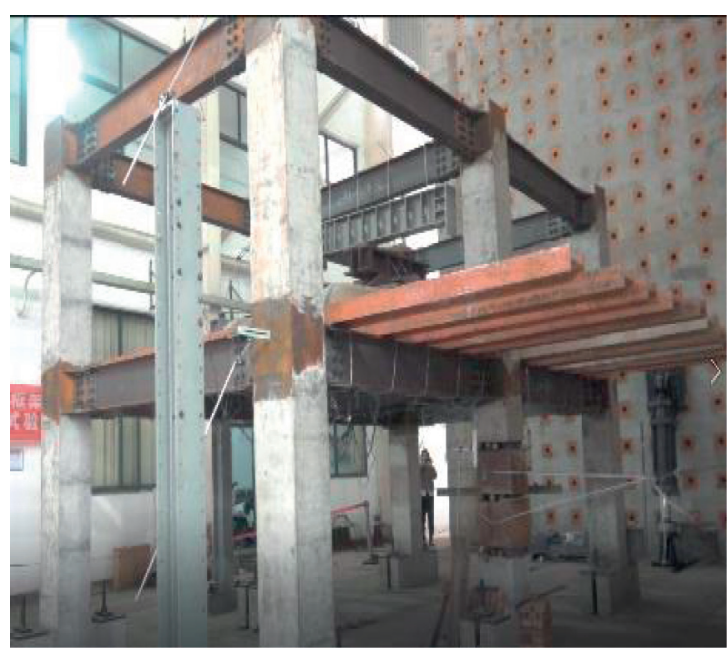

(a)

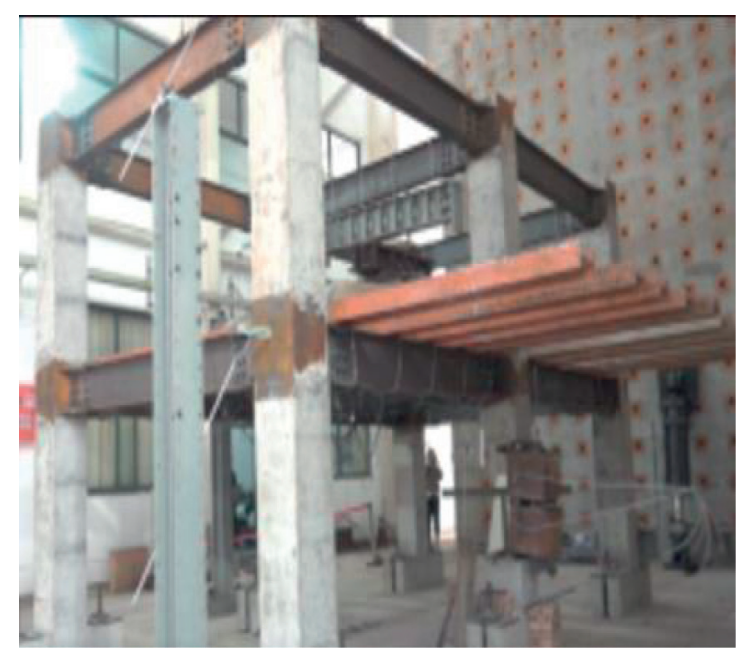

(b)

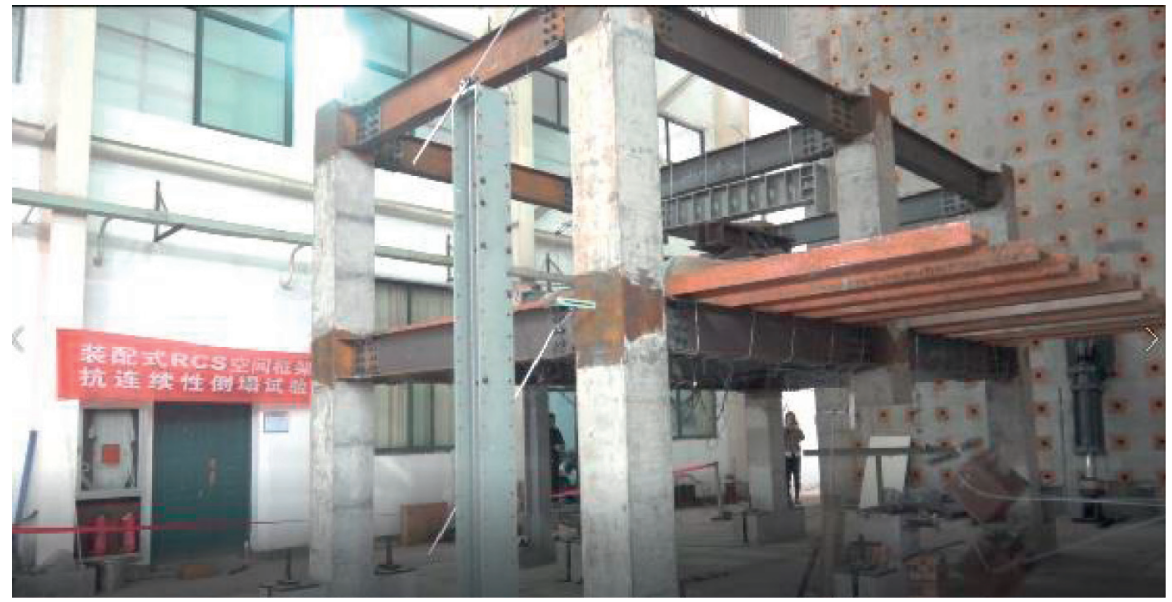

(c)

FIgURe 13: Photos of the failure process.

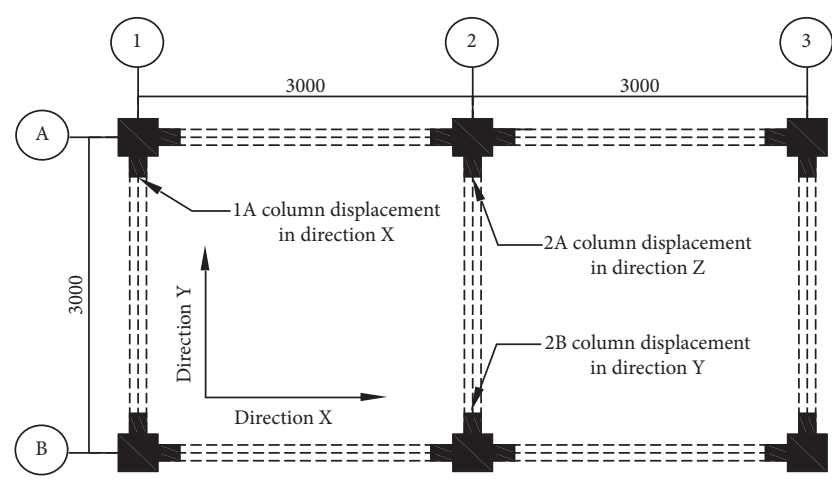

FIGURE 14: Displacement test points.

Joint 1 is shown in Figure 19(a). The clearance of $15 \mathrm{~mm}$ increases rapidly at the moment of column $2 \mathrm{~A}$ failure. Bolts slip slowly with a small slip noise, and the local bending deformation of the lower flange steel plate B can be clearly observed as time progresses. The author believes that the clearance of $15 \mathrm{~mm}$ becomes the maximum because joint 1 was pulled out in the $X$ direction by the steel beam with a slight angle. Deformation of the steel plate stops when the experimental model is stable.

Joint 2 is shown in Figures 19(b) and 19(c). The load acts again on the steel beam between columns $1 \mathrm{~A}$ and $2 \mathrm{~A}$ and causes the lower flange plate $\mathrm{B}$ to dislocate and deform at the clearance of $15 \mathrm{~mm}$ when the instantaneous displacement of column $2 \mathrm{~A}$ in the $Z$ direction reaches the peak value because the load lags behind the $Z$ displacement of column 2A in time. The upper flange of the joint steel hoop and the upper flange of the steel beam form complete whole and then settle down with the rotation center of $15 \mathrm{~mm}$ clearance, and the steel plate A is slightly end camber at the right end.

Joint 3 is shown in Figure 19(d). Column A2 can form the catenary structure in the $X$ direction and the cantilever structure in the $Y$ direction. The rotational stiffness of the $Y$ direction is significantly less than that of the $X$ direction, and the load is mainly borne by columns A1 and A3. Therefore, compared with joint 1 , joint 2 , and joint 4 , the steel plate of joint 3 presents microdeformation.

Joint 4 is shown in Figure 19(e). The lower flange steel plate $\mathrm{B}$ continues to dislocate and deform at the clearance 


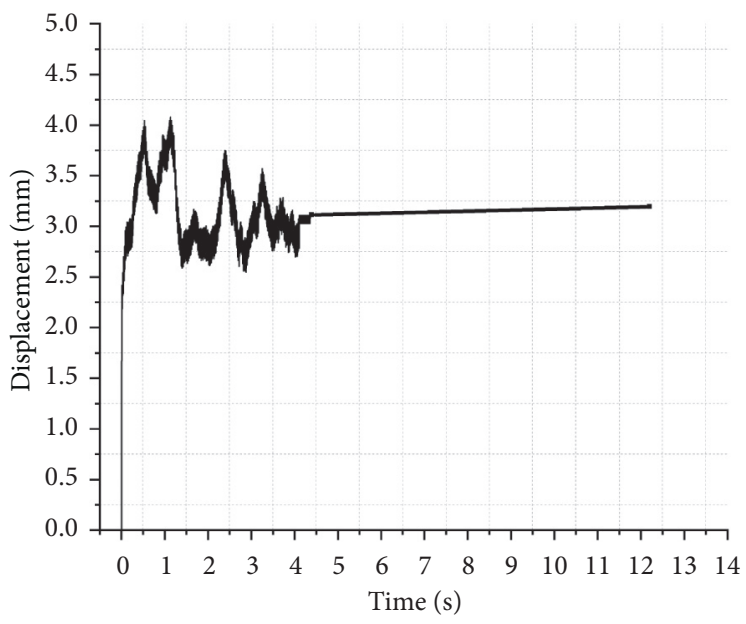

(a)

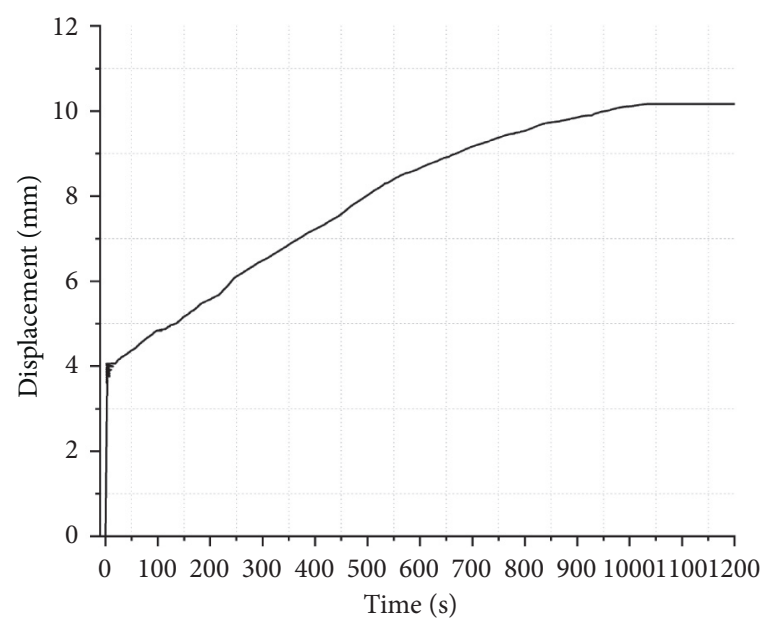

(b)

Figure 15: Time history curve of the failure column displacement in the $Z$ direction. (a) Time history curve within $14 \mathrm{~s}$. (b) Time history curve within $1200 \mathrm{~s}$.

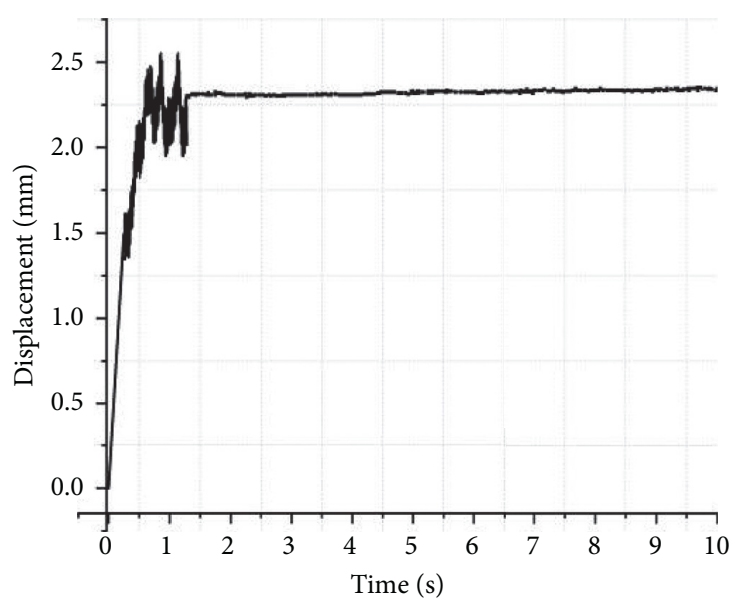

(a)

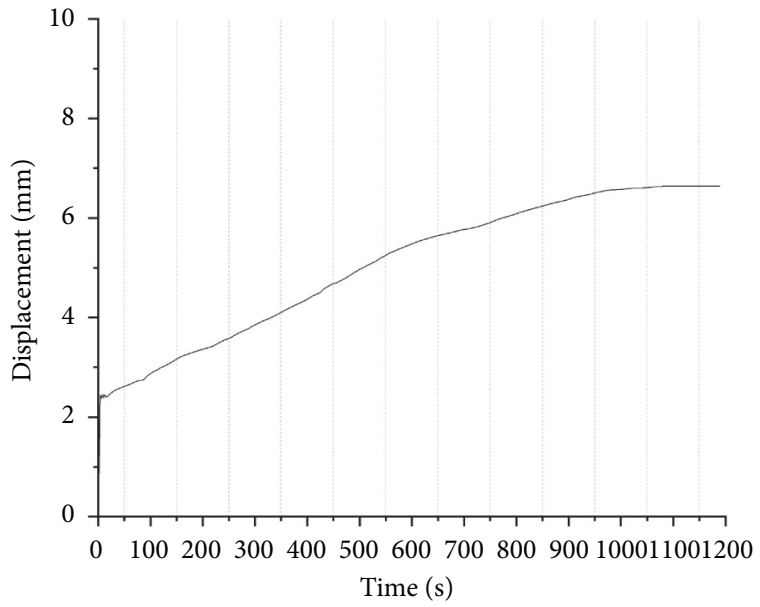

(b)

Figure 16: Time history curve of column 2B displacement in the $Y$ direction. (a) Time history curve within $10 \mathrm{~s}$. (b) Time history curve within $1200 \mathrm{~s}$.

of $15 \mathrm{~mm}$ as time progresses. Column A2 presents a slight rotating phenomenon in the positive $X$ direction but depends on the lateral stiffness of adjacent columns and can completely resist the instantaneous failure of column $2 \mathrm{~A}$.

In summary, concrete cracking, joint steel hoop deformation, and steel beam failure were absent in the experimental process. Hence, the prefabricated RCS composite frame structure adopts the "new RCS beam-tocolumn connection" [20] as the beam-to-column connection method demonstrates enhanced resistance to progressive collapse. Only the steel plate shows local deformation in the experimental model, but the overall stability of the structure remains satisfactory and can be reinforced by replacing the steel plate in the later period.
The final overall photo of the experimental model is shown in Figure 20.

\section{Numerical Analysis}

The completed static collapse experimental results based on the "new RCS beam-to-column connection" [20] were applied to the SAP2000 FEM program to describe the beam-tocolumn connection of the experimental model, and the nonlinear dynamic method was used for numerical analysis. The numerical analysis results were compared with the experimental results to verify the effectiveness of the numerical analysis. The failure time of column $2 \mathrm{~A}$ is set to a maximum of 0.1 times the vertical fundamental period of the remaining structure, and the calculation step length of the 


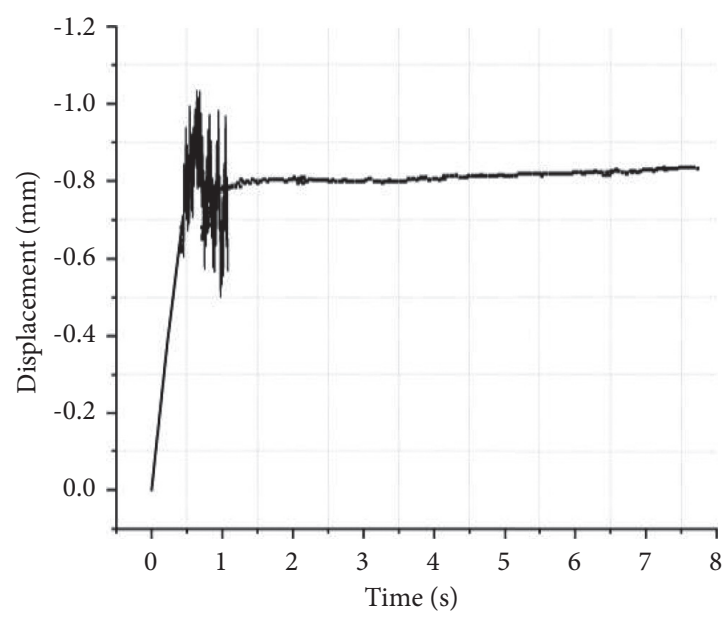

(a)

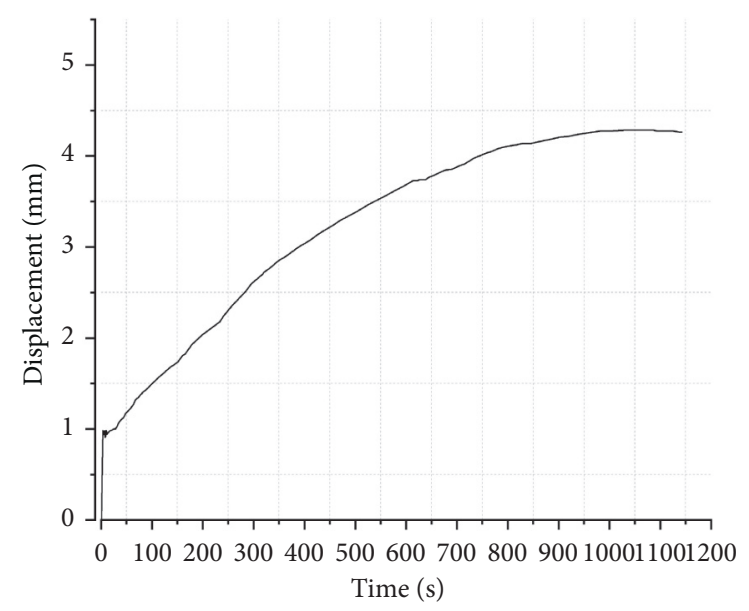

(b)

Figure 17: Time history curve of column 1A displacement in the $X$ direction. (a) Time history curve within 8 s. (b) Time history curve within $1200 \mathrm{~s}$.

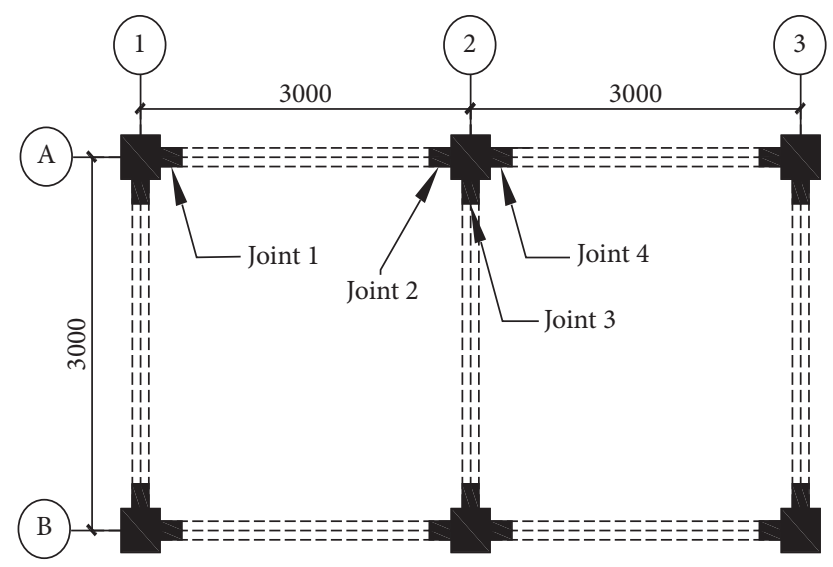

FIGURE 18: Joint numbers.

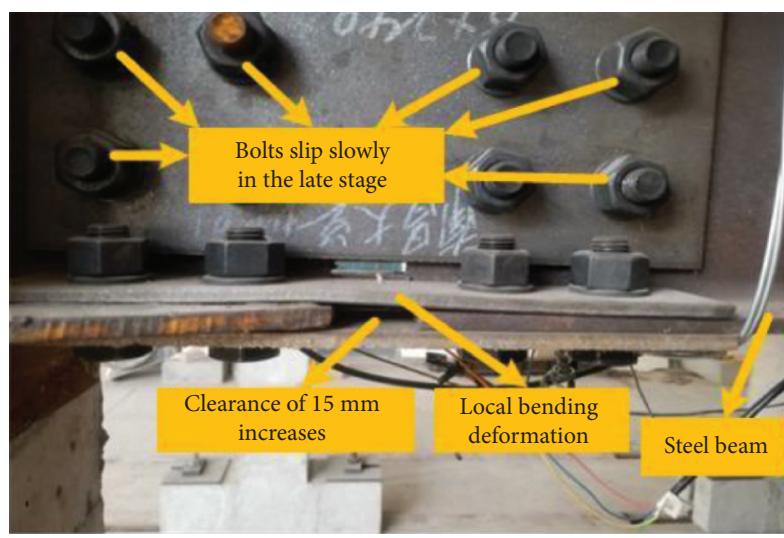

(a)

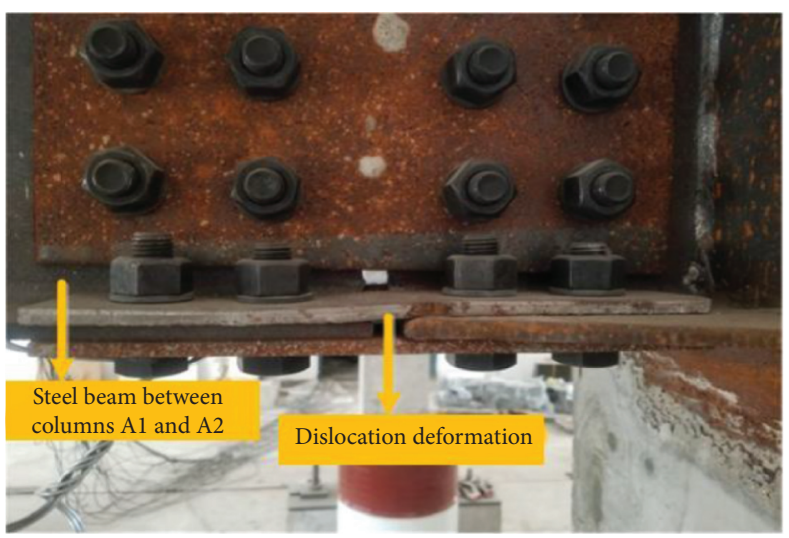

(b)

FIgUre 19: Continued. 


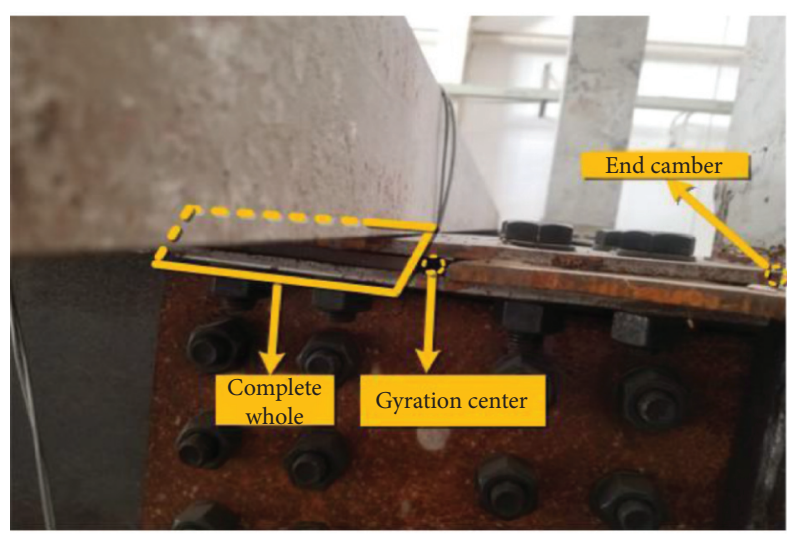

(c)

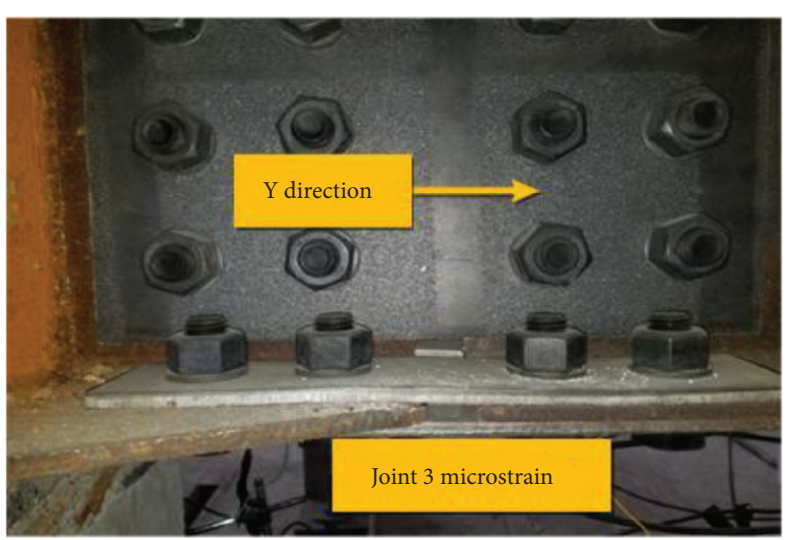

(d)

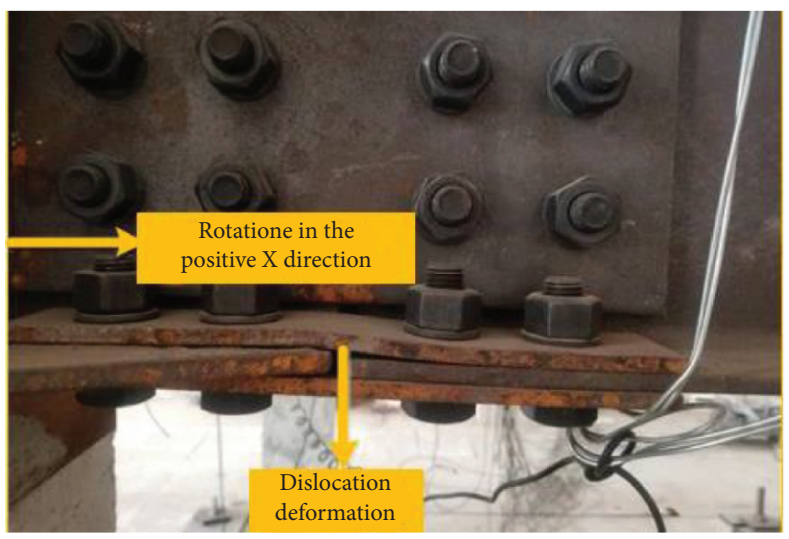

(e)

Figure 19: Deformation photos of steel plates (A, B, and C). (a) Joint 1, (b) joint 2, (c) joint 2, (d) joint 3, and (e) joint 4.

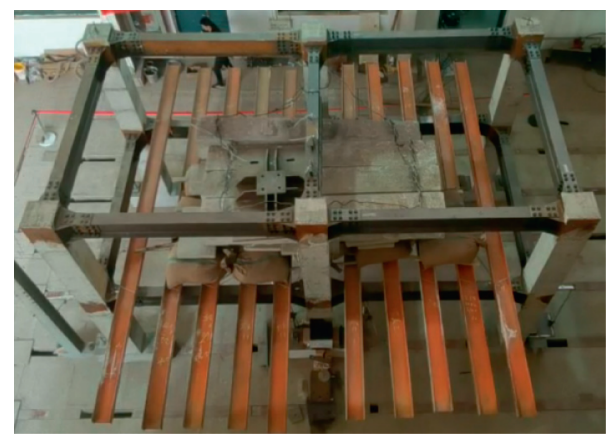

FIgURE 20: Final overall photo of the experimental model.

time history condition is set to a maximum of $0.005 \mathrm{~s}$ to simulate the actual experimental process. The first period is 0.9 times the vertical period and the second period is 0.25 times the vertical period when Rayleigh damping is considered, as described in Table 2, where $T_{v}$ is the vertical period. The finite-element model is shown in Figure 21.

The comparison between the finite-element and experimental numerical result is shown in Figures 22(a), 22(b), and 22(c). Joint 11 in the $Z$ direction, joint 10 in the $X$ direction, and joint 8 in the $Y$ direction rapidly reach the peak displacement, and then the reciprocating vibration attenuation occurs along the displacement direction at the failure moment of column A2. The vibration stops until the dynamic attenuation reaches 0 , and the structure enters a stable development period.

The finite-element numerical result of column $2 \mathrm{~A}$ in the $Z$ direction stabilized at $3.58 \mathrm{~mm}$ after $12 \mathrm{~s}$, and the experimental numerical result stabilized at $3.23 \mathrm{~mm}$ after $12 \mathrm{~s}$. The finite-element numerical test of column A1 in the $X$ direction stabilized at $0.898 \mathrm{~mm}$ after $4 \mathrm{~s}$, and the experimental numerical result stabilized at $0.882 \mathrm{~mm}$ after $1.2 \mathrm{~s}$. 
TABle 2: Parameter of the FEM.

\begin{tabular}{lcccc}
\hline Natural period (s) & Participating mass ratios (\%) & First period & Second period & Damping ratio \\
\hline 0.4 & 90 & $0.9 T_{v}$ & $0.25 T_{v}$ & 0.05 \\
\hline
\end{tabular}

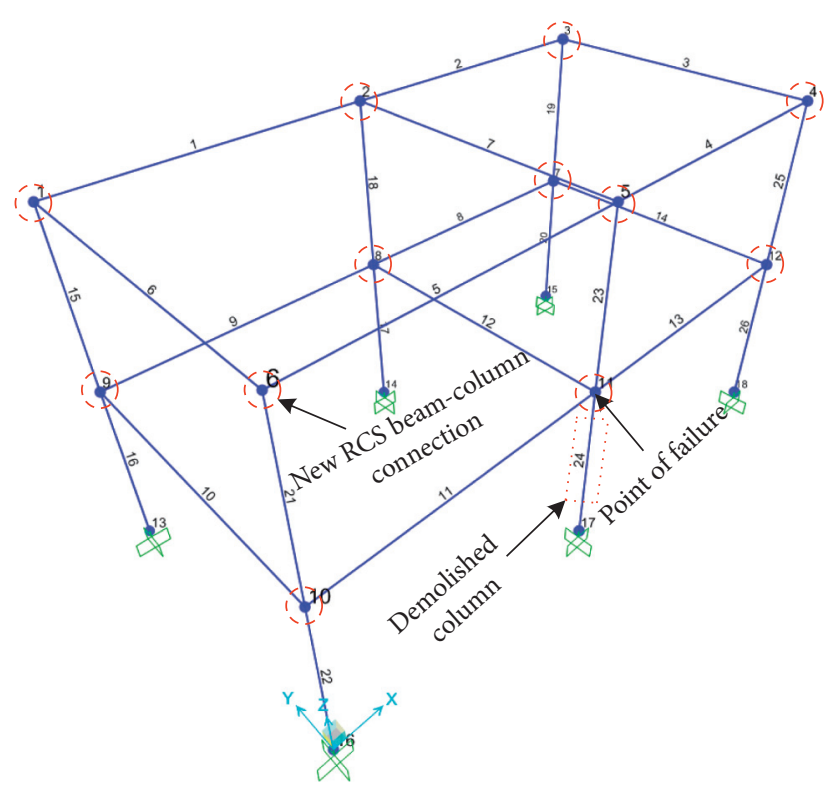

Figure 21: Finite-element model.

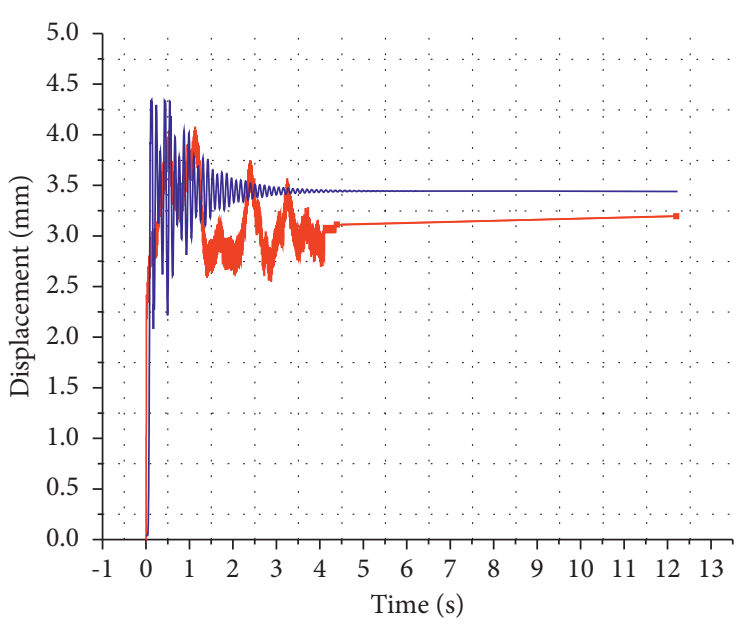

_ Experimental numerical

- Finite-element numerical

(a)

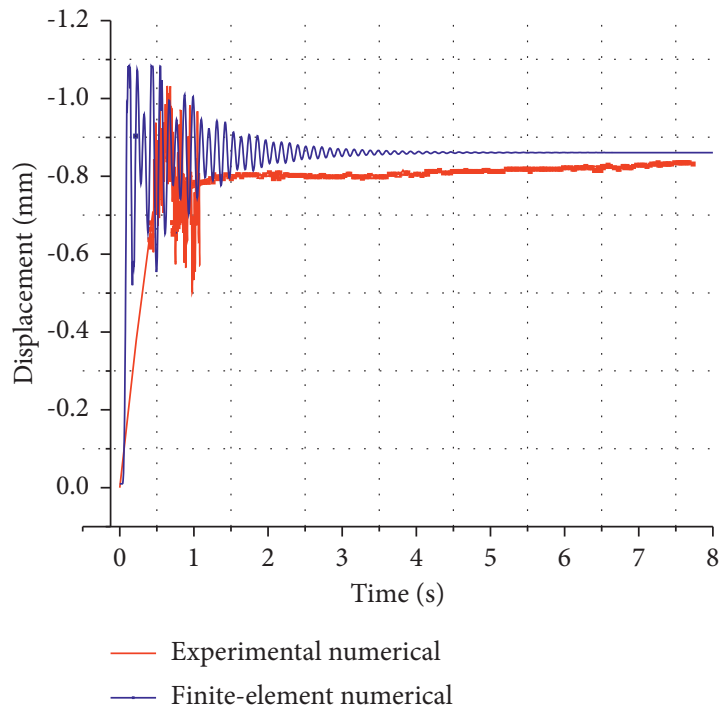

(b)

Figure 22: Continued. 


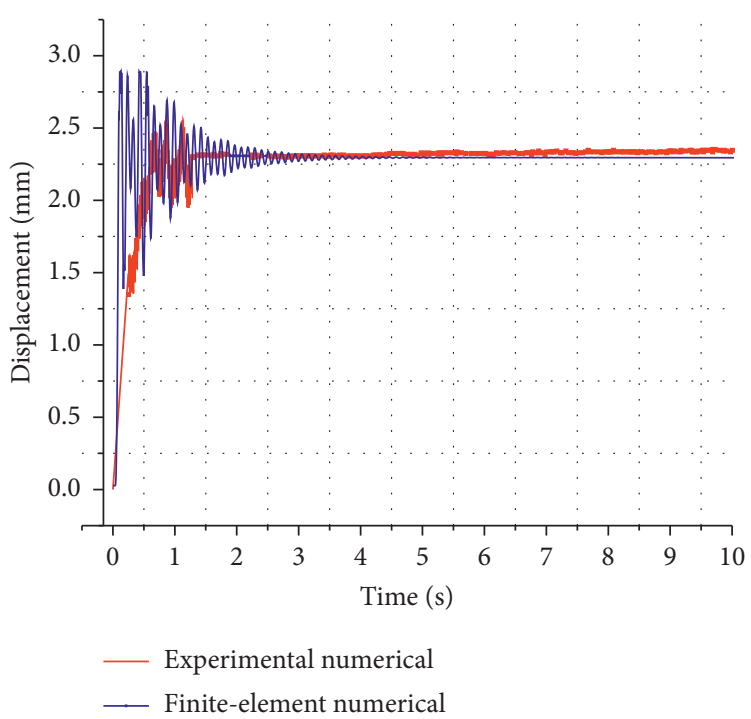

(c)

Figure 22: Displacement comparison chart of experimental and finite-element results. (a) Time history curve of column 2A displacement in the $Z$ direction. (b) Time history curve of column $1 \mathrm{~A}$ displacement in the $X$ direction. (c) Time history curve of column $2 \mathrm{~B}$ displacement in the $Y$ direction.

$$
R_{d}=\frac{y_{\max }}{y_{s t}}
$$

where $R_{d}$ is the dynamic amplification factor, $y_{\max }$ is the peak displacement, $y_{s t}$ is the static displacement. The maximum $R_{d}$ is at column $2 \mathrm{~A}$, where $y_{\max }=4.07 \mathrm{~mm}, y_{s t}=3.19 \mathrm{~mm}$, and $R_{d}=1.27586$. Therefore, we suggest that $R_{d}$ is 1.28 .

The experimental numerical result failed to reach the finite-element numerical result due to the distortion, filtering, and other reasons in the dynamic test. The elastic modulus of the material increases to a certain extent in the case of high velocity, thereby indicating that the experimental numerical result is less than the finiteelement numerical result. However, the overall trend of finite-element and experimental numerical results is consistent.

\section{Summary and Conclusions}

This study adopts the "new RCS beam-to-column connection" [20] that our group developed as the experimental model of the beam-to-column connection type. Experimental and numerical simulation analyses of the progressive collapse resistance of the prefabricated RCS space frame structure were carried out to investigate the progressive collapse resistance and characteristics of the prefabricated RCS composite frame structure with sudden failure of side columns. The following conclusions can be drawn from this study:

(1) The later deformation numerical result of the remaining structure is 3.6 times the maximum numerical result of the instantaneous deformation. (a) The instantaneous maximum numerical result is significantly less than the later deformation numerical result. (b) The dynamic response increases the elastic modulus of the material, and the structural deformation is reduced. (c) The bolt slip consumes the vibration energy of the structure. Hence, the dynamic effect demonstrates no significant influence on the prefabricated RCS composite frame structure, and the suggested dynamic amplification coefficient is 1.28.

(2) The consistency between FEA and experimental results verified that the static collapse experimental results of the "new RCS beam-to-column connection" [20] applied in SAP2000 to describe the experimental joint model are reliable.

(3) The steel plate of the beam-to-column connection is the weak part of the structural failure. Therefore, appropriate measures should be applied to strengthen the steel plate of the beam-to-column connection when the prefabricated RCS composite frame structure is designed to resist progressive collapse.

(4) Although some steel plates are slightly deformed, the overall stability of the remaining RCS structure remains intact. This finding indicated that the prefabricated RCS composite frame structure designed in accordance with Chinese building codes [23-25] demonstrates better performance in resisting progressive collapse.

\section{Data Availability}

The data used to support the findings of this study are available from the corresponding author upon request.

\section{Conflicts of Interest}

The authors declare that there are no conflicts of interest.

\section{Acknowledgments}

The authors gratefully acknowledge the financial support provided by the National Natural Science Foundation of 
China (51768044). The authors are also very grateful to "Yuchen Wang" and "Moqiang Xiong" for their help in this research.

\section{References}

[1] I. Nishiyama, H. Kuramoto, and H. Noguchi, "Guidelines: seismic design of composite reinforced concrete and steel buildings," Journal of Structural Engineering, vol. 130, no. 2, pp. 336-342, 2004.

[2] E.-J. Lee, J.-H. Moon, and M.-S. Lee, "Shear resistance contribution of constituent elements consisting RCS joint," Advances in Civil Engineering, vol. 2021, Article ID 3958247, 14 pages, 2021.

[3] L. G. Griffis, "Some design considerations for composite frames structures," AISC Engineering Journal, vol. 23, no. 2, pp. 59-64, 1986.

[4] T. M. Sheikh, G. G. Deierlein, J. A. Yura, and J. O. Jirsa, "Beam-column moment connections for composite frames: part 1," Journal of Structural Engineering, vol. 115, no. 11, pp. 2858-2876, 1989.

[5] G. G. Deierlein, "Beam-column moment connections for composite frames Part 2," Journal of Structural Engineering, vol. 115, 1989.

[6] R. Kanno, Strength, Deformation and Seismic Resistance of Joint between Steel Beam and Reinforced concrete Columns, Cornell University, New York, NY, USA, 1993.

[7] R. Kanno and G. G. Deierlein, "Seismic behavior of composite (RCS) beam-column joint subassemblies," in Proceedings of the Composite Construction in Steel and Concrete III, Engineering Foundation Conference, pp. 236-249, Irsee, Germany, June 1996.

[8] G. J. Parra-Montesions and J. K. Wight, "Seismic response of exterior RC columns-to-steel beam connections," Journal of Structural Engineering, vol. 126, no. 10, pp. 1113-1121, 2000.

[9] X. Liang and J. Gustavo, "Seismic behavior of reinforced concrete column-steel beam subassemblies and frame systems," Journal of Structural Engineering, vol. 130, no. 2, pp. 310-319, 2004.

[10] C.-T. Cheng and C.-C. Chen, "Seismic behavior of steel beam and reinforced concrete column connections," Journal of Constructional Steel Research, vol. 61, no. 5, pp. 587-606, 2005.

[11] L. B. Fargier-Gabaldon, J. Gustavo, and G. J. Parra-Montesinos, "Behavior of reinforced concrete column-steel beam roof level T-connections under displacement reversals," Journal of Structural Engineering, vol. 132, no. 7, pp. 10411051, 2006.

[12] J. R. Hayes, S. C. Woodson, R. G. Pekelnicky, C. D. Poland, W. G. Corley, and M. Sozen, "Can strengthening for earthquake improve blast and progressive collapse resistance?" Journal of Structural Engineering, vol. 131, no. 8, pp. 11571177, 2005.

[13] M. Sasani, M. Bazan, and S. Sagiroglu, "Experimental and analytical progressive collapse evaluation of actual reinforced concrete structure," ACI Structural Journal, vol. 104, no. 6, pp. 731-739, 2007.

[14] K. A. Seffen, "Progressive collapse of the world trade center: simple analysis," Journal of Engineering Mechanics-ASCE, vol. 134, pp. 125-132, 2008.

[15] Y. Bao, S. K. Kunnath, S. El-Tawil, and H. S. Lew, "Macro model-based simulation of progressive collapse: RC frame structures," Journal of Structural Engineering, vol. 134, no. 7, pp. 1079-1091, 2008.
[16] General Services Administration, Progressive Collapse Analysis and Design Guidelines for New Federal Office Buildings and Major Modernization Projects, GSA, Washington, DC, USA, 2003.

[17] Department of Defense, Unified Facilities Criteria: Design of Buildings to Resist Progressive collapse, CreateSpace, Scotts Valley, CA, USA, 2010.

[18] Japanese Society of Steel Construction Council on Tall Buildings and Urban Habitat, Guidelines for Collapse Control Design, 2005.

[19] J. Xiong, Y. Li, Z. Wu, G. Hou, and Y. He, "Mechanism of progressive collapse resistance of reinforced concrete spatial frame structure," in Proceedings of the 12th International Symposium on Structural Engineering, pp. 1390-1394, Wuhan, China, December 2012.

[20] Z. Li and J. Xiong, "A connection mechanism of beam-column joints in RCS composite structure. CN210713245U," 2020.

[21] Y. Xiao, S. Kunnath, F. W. Li, and Y. B. Zhoa, "Collapse test of three-story half-scale reinforced concrete frame building," ACI Structural Journal, vol. 112, no. 4, pp. 429-438, 2015.

[22] H. E. Qing-Feng and Y. I. Wei-Jian, Experimental Study on Collapse-Resistant Behavior of RC Frame Structures in Explosion Demolition, CNKI, Beijing, China, 2017.

[23] Ministry of Housing and Urban-Rural Development of the People's Republic of China (MOHURD), Code for Design of Concrete Structures (GB50010-2010), Beijing, China, 2010.

[24] Ministry of Housing and Urban-Rural Development of the People's Republic of China (MOHURD), Code for Seismic Design of Buildings. (GB50011-2010), Beijing, China, 2010.

[25] Ministry of Construction of the People's Republic of China (MOHURD), Code for Design of Steel Structures (GB500172017), Beijing, China, 2013, in Chinese.

[26] X. Zhao and A. Qi, "Slotted beam-column energy dissipating connections: applicability and seismic behavior," Advances in Civil Engineering, vol. 2021, Article ID 5530083, 16 pages, 2021.

[27] Q. Liu, S. Chen, W. Lin, and F. Zeng, "Experimental study on novel energy-dissipating prefabricated beam-column joints," Advances in Civil Engineering, vol. 2019, Article ID 8151087, 17 pages, 2019. 